https://doi.org/10.48009/1_iis_2005_372-378

\title{
INNOVATIVE IS PROJECT MANAGEMENT PEDAGOGY: COMBINING REAL WORLD PROJECTS AND ACTION LEARNING
}

\author{
Dr. Sean T. McGann, Ohio University, mcgann@ohio.edu \\ Matthew A. Cahill, Ohio University, mc160200@ohio.edu
}

\begin{abstract}
The demand for IS project management skills in today's business environment is strongly supported by current research. Our review of IS curriculum guidelines such as IS 2002 [2] shows that there is also a call for a heavy emphasis on project management in modern IS pedagogy. However, research also shows that there are few models that do so [10]. In this paper, we move towards filling this pedagogical gap by presenting a unique approach to teaching IS project management. This approach combines real-world projects with conceptual materials using action learning principles. We present some of these techniques and then discuss preliminary findings of our study which validates this approach and its techniques.
\end{abstract}

Keywords: Project management, IS Capstone, action learning, IS pedagogy

\section{INTRODUCTION}

In order to keep pace with the turbulent business environment of the $21^{\text {st }}$ century, modern businesses have largely become "project organizations." This is especially true in the case of IS departments, where the dynamic nature of information systems often drives a continuous stream of critical projects. Past research shows that the stakes are much higher in IS projects, as they usually represent significant financial investment and their failure can lead to organizational demise [6]. Given the increasing importance of IS projects in today's organizations, it is interesting that so many of them fail to meet their basic goals or are cancelled altogether. Duncan [3] found that only $13 \%$ of information technology (IT) projects were considered successful while only $16.2 \%$ were completed on time and within budget. As a result, IS project management skills are in great demand due to their potential to increase project success.

We therefore argue for the importance of IS curricula including project management as a key area of emphasis. However, our review of existing IS curriculum models revealed that this has not been the case. To fill this pedagogical gap, this paper presents eight innovative methods, developed by the Ohio University (OU) MIS Department, for teaching IS project management. Our approach is grounded in real-world IS projects that put all students in the role of the project manager with full autonomy. We leverage action learning principles [9] to transform the task environment (student projects) into a project management classroom and to make the tasks (e.g., project leadership, risk management, project planning, change management and teambuilding) the learning vehicle. Preliminary results of a technique-effectiveness study and future research opportunities are also presented.

\section{Project Management Literature}

\section{LITERATURE REVIEW}

We have established that IS project management skills are a key to success in today's business world. Specifically, Lee [7] found that project managers must possess skills in four knowledge areas: technical specialties, technology management, business functions, and interpersonal 
communications and management. These project management skills have become necessary in every major IS-related field, from technical writer to consultant [8]. However, our review shows that there is a recognized lack of IS professionals with this necessary skill set. In 2003, more than $75 \%$ of 219 top IT executives interviewed by the Meta Group indicated that a lack of in-house project management skills is a major issue for them [5]. Further compounding the problem is the deficiency of project management training available to IS professionals once they enter the workforce. The Meta Group found that less than 15\% of the organizations polled have IS project management training programs in place [5]. Given the recognized lack of project management skills in the IS field, and the inability of organizations to provide IS project management training, we argue that it is increasingly vital for IS curricula to focus on developing these skills.

\section{IS Curriculum Literature}

A review of current IS curriculum models shows that project management is seen as a key skill set [2]. However, project management is typically not taught in current IS curricula. In a comparison of the undergraduate IS curricula in five major business schools [10], it was found that none of the institutions offered a course in the project management category as recommended in the IS 2002 model curriculum. Further review of the literature shows that even when IS project management is incorporated into IS courses, typical pedagogical methods (e.g., case studies, computer simulations and project management internships) for teaching such skills are largely ineffective, as they do not sufficiently integrate the multitude of social and technical lessons and experience [4]. Also, these methods have traditionally provided instruction in only basic areas such as how to plan, organize, and manage a series of technical tasks. Other aspects, such as risk management, team dynamics, change management, status reporting, estimation and client relations must also be taught to produce well-rounded IS project managers who understand and can manage the non-technical aspects of a project [1].

\section{Summary}

A review of the project management and IS curriculum literature shows that there is a need for IS professionals with strong project management skills. Although literature such as the IS 2002 curricula model calls for courses designed to teach these skills, we found that project management is typically not emphasized in undergraduate IS curricula. Further, even when project management is incorporated, traditional pedagogical methods prove ineffective at teaching the variety of skills needed to manage today's complex IS projects. Therefore, we argue that new techniques, such as those that follow, are needed to effectively teach IS project management.

\section{EIGHT UNIQUE IS PROJECT MANAGEMENT TEACHING TECHNIQUES}

Our IS project management teaching takes place primarily in the IS Capstone Series. This course is divided into two tightly-integrated segments: course content and execution of the client project. Course content is delivered through relevant project management readings, applied case studies, engaging discussions, and related activities. Most importantly, we leverage action learning principles by using activities which require students to immediately apply course content in the execution of their project. Below we provide descriptions of our key pedagogical techniques, discussing our approach and lessons learned over the past 5 years. We also add contextual quotes from students who have taken the course (data collection methods for obtaining these quotes are explained in "Illustrative Data") to support these techniques. 


\section{Actual Client Project}

Students assume the role of IS consultants to complete a complex systems development project for an actual, "real-world" client in the span of 10 weeks. Throughout the project, students adhere to the phases and steps of the systems development lifecycle (SDLC) to deliver an application that fulfills the client's business need. Students first work with the client to gain an understanding of their current business processes and determine the requirements for the application. They then utilize ASP.NET supported by a Microsoft Access database to design and develop an application tailored to the client's specifications. Throughout the project, students are in constant contact with the client to ensure satisfaction, manage the relationship and respond to client issues.

Lessons Learned. We found that the client project, in conjunction with traditional conceptual activities, is more effective at teaching IS project management skills than conceptual methods alone. As a present student observed: "The client project was good at teaching basic project management skills because it provided a real life environment where you had to quickly apply what you learned in class." (Present Student 1)

We also found that the client project taught students how to effectively communicate with nontechnical clients - a skill that is highly valued in today's business world yet is difficult to teach in a traditional classroom setting. Another present student expressed the importance of this skill as follows: "Having that real-life experience means you understand how to deal with clients at all different levels and [how] to keep them informed and happy." (Present Student 2)

\section{Rotating Role of Project Manager}

There are typically 4 or 5 students on each project team. Every two weeks, a different team member assumes the role of project manager, ensuring that each student has an opportunity to practice these skills. As project manger, students are held accountable for the progress of the project and must keep an updated project plan (which can be requested by the instructor at any time), lead all team meetings, act as the primary interface with the client, and give formal status report presentations at the end of each class session.

Lessons Learned. We found that by rotating the role of project manager, ALL students are provided with an opportunity to put the project management skills they have learned in the classroom into practice. Also, this technique gives every student an opportunity to experience first hand what it is like to be responsible for a complex IS project. Quotes such as the following are evidence that this opportunity was perceived as highly valuable because it forced students to apply project management skills and assume a high level of responsibility for this complex engagement: "I couldn't believe that as an undergraduate student I was solely responsible for our project and expected to manage our client, our project, our resources, and our time!" (Present Student 3) "[it] allowed us to be project leads on certain phases of the SDLC, which allowed us to use project management skills that we had learned. I think it definitely helped everyone feel more comfortable standing up and taking the lead at some point in time." (Present Student 4) 


\section{Project Management Workshop}

The project management workshop consists of four class periods devoted specifically to the topic of IS project management. During this time, a series of project management lectures intended to introduce important concepts (such as project management's relationship to the SDLC and the nuances of IT projects that separate them from other projects) is presented. After each lecture, an open discussion about project management is held. Throughout this discussion, students are encouraged to share their past project management experiences from this class, other classes or prior internships.

Lessons Learned. We found that students enjoy the opportunity to hear about each others' project management experiences. Doing so allows them to learn what has and has not been effective on past projects. This in turn allows them to take advantage of each other's knowledge throughout the course of their client projects. A current student said of the value of these discussions: "I like the project management discussions. I thought they were very helpful and I learned a lot from them because it really put what we were learning into the perspective of our projects." (Current Student 3)

\section{Classic Mistakes Case Studies and Activities}

After assigned readings concerning the people, process, product, and technology-related "classic mistakes" associated with systems development projects, students analyze case studies and identify classic mistakes present. They then examine their own client projects and identify areas where they should be wary of committing these mistakes or where they have seen them emerge. Once this is complete, each team's current project manager reports their findings to the class.

Lessons Learned. We found that sharing each group's findings fosters a greater awareness of the many mistakes that can be made when managing an IS project. By understanding the potential for these mistakes during their client projects, we found that students are much better able to avoid them. Regarding the effectiveness of this activity, a present student remarked: "I understand more of the basic aspects of project management, including how to avoid making the classic mistakes. As a result, we have been more proactive about preventing them." (Present Student 5)

\section{Risk Management Case Studies and Activities}

Immediately following a reading assignment and related case study pertaining to risk management, each team performs a thorough risk assessment on their client project and documents their "top ten list" of project risks. They then create a plan that specifies how each potential risk will be mitigated and how it will be dealt with should it occur. Throughout this process, one team member acts as the "Risk Officer" who is charged with playing devil's advocate for the quarter, looking for risks at every step of the project. The project manager then reports the team's assessment and mitigation strategy to the entire class.

Lessons Learned. We found that, like the Classic Mistakes activity, this exercise cultivates a shared learning experience where teams become aware of potential risks on their own projects by hearing about those that may occur on other team's projects. This in turn provides all teams with a greater understanding of the risks that are present in systems development projects. Present Student 6 observed the following with regards to this activity: "taking our project and actually 
identifying the risks helped us better learn risk assessment and mitigation. I see how important it is now to project management." (Present Student 6)

\section{Project Planning Activities}

After an assigned reading dealing with project planning and scheduling, students use Microsoft Project to create an initial project plan for their client projects. The project plan encompasses each phase of the SDLC and details the project timeline, project milestones, tasks and subtasks to be performed to achieve those milestones, and which team members are responsible for given tasks. The project plan is updated no less than five times throughout the quarter to reflect any changes that occur throughout the course of client project. The project manager is responsible for updating the project plan and also presenting it to the entire class at weekly status meetings. The instructor can collect and review each team's project plan at any time.

Lessons Learned. We found that creating a project plan is an excellent way for teams to gain a comprehensive understanding of what tasks need to be completed in order for their projects to be successful. However, merely creating the project plan is not enough. To be successful, teams must constantly update their project plans to account for any unplanned changes that may occur during their project. Doing so keeps the entire team up to date and aware of exactly what needs to be accomplished in order for their project to be completed on time, while meeting the client's needs. Present Student 7's comments were typical with regards to this activity: "The client project forced you to learn how to use a project plan and actually stick to it. We got lots of practice, were forced to live by it, and it became a way of life for us." (Present Student 7)

\section{Estimation Case Study and Activity}

After a reading assignment and related case study concerning estimation, teams are required to identify the modules that will need to be developed for their client's system. Once all the necessary modules have been identified, teams estimate the time and labor requirements that will be needed to complete the development process. These estimations are then incorporated into the project plan in the form of task due dates and assignments. The project manager presents the team's methods and results to the class for discussion.

Lessons Learned. We found that this activity combines project planning and system analysis skills to foster a deeper understanding of their projects and what it will take to complete them. This is the first time that the students are forced to take the requirements they have solicited and look in detail at the effort it will take to execute the project. The effectiveness of this activity was confirmed in a survey (methods outlined below) as follows: when asked if they had the ability to effectively estimate requirements for a project and distribute resources accordingly, $67 \%$ of past students agreed while $8 \%$ strongly agreed ( $25 \%$ neutral). Of current students, $44 \%$ strongly agreed, $22 \%$ agreed, and $33 \%$ were neutral.

\section{Weekly Status Meetings}

Status meetings are held once or twice a week throughout the duration of the client project. During this time, each team's project manager uses the project plan to update the rest of the class on the details of his/her team's client project. Issues and concerns from each team's project are discussed openly and solutions and suggestions are offered by all teams. 
Lessons Learned. We found that the status meetings were the most vital group activity in the class. It is during these sessions that the group hears how other groups' projects are progressing and discovers if any issues have arisen throughout the project. By learning what problems other teams have faced and how they overcame them, all teams are able to recognize and avoid potential pitfalls. Past Student 2 supported this value proposition as follows: "The open discussions we had where each group was able to share their experiences with their client really got you thinking about other issues that could come up in your project. That was a big advantage and I felt it was the most valuable part of the project management part."

\section{Methodology}

\section{ILLUSTRATIVE DATA}

We conducted a year-long study of the OU Capstone Series to validate the pedagogical techniques described above. Due to page constraints, we present a small segment of this data to illustrate the spirit of our findings, which were largely positive (negative viewpoints were expressed, but are not presented in this brief format, as they represented less than $5 \%$ of our data). In this study we used a number of data sources to help triangulate our findings, including (1) A year of anonymous capstone course evaluations. (2) Surveys of 30 present and past capstone students. (3) 30-minute phone interviews with 15 past students working in various IS positions. (4) An hour-long focus group with five present capstone students.

\section{Initial Findings}

Our empirical research suggests that our unique pedagogical approach to teaching IS project management skills is highly effective. Throughout our interviews, both present and past students acknowledged that because of the Capstone Series they feel they have a broad range of project management skills. Our survey data shows that $97 \%$ of past students and $95 \%$ of present students surveyed agree or strongly agree that they have the potential to become capable project managers as a result of the capstone series (5-point scale - strongly disagree, disagree, neutral, agree, strongly agree). In addition to simply learning project management skills, our research suggests that both present (94\%) and past students (98\%) agree or strongly agree that they have stronger project management skills than peers who did not have this course.

Other key findings that validate our approach include the following: 1) Present students noted that their project management skills separate them from other students seeking IS positions, as exemplified by the following quote: "Having any kind of 'jump' on other people in the marketplace is definitely important, and my project management skills from the capstone have given me an advantage." (Past Student 7) 2) Past students have noticed that the project management skills they developed in the Capstone Series set them apart from peers at their level who do not possess the same training. This was a typical sentiment: "While my technical skills weren't as strong coming out of school as my counterparts, I was able to be more effective due to my ability to manage tasks and projects with other workers" (Past Student 3). 3) As a result of their superior skills, we found that our students were better positioned to move into project management roles than peers who had not had a similar capstone experience. Present Student 6 explained: "By understanding how to coordinate a project, a team, and the resources needed, I believe that I am well armed with the skills and abilities needed by a project manager." 4) Past students acknowledged that the project management skills they learned during the Capstone Series made them more likely to assume project management roles than their peers. Past Student 
4 summarized as follows: "It makes us more eligible to move up in the workplace as team leads. It also gives us the confidence to take on a supervisory role." 5) Students also noted that because they were already equipped with basic project management skills, they were able to learn more advanced project management abilities faster than their peers. As explained by Past Student 5, "I think that it gave me a great head start on learning the basics of project management. Since I already had the basics when I came to [my company] I could start focusing on higher level project management, which has helped my career."

\section{DISCUSSION AND CONCLUSION}

In summary, in today's project organizations, IS project management skills are increasingly vital. As a result, IS professionals who possess a project management skill set are in high demand. Unfortunately, project management is not typically taught in IS courses, even though the 2002 IS model curricula calls for courses designed specifically to teach this skill area. Even when project management is taught, traditional teaching methods have proven largely ineffective. Preliminary results indicate that our pedagogical approach to teaching IS project management is highly effective. Not only do our students gain basic project management skills, they also report that their skills are stronger than entry-level candidates from other MIS programs. In addition, our research shows that as a result of the MIS Capstone Series, our students feel they are positioned more favorably to move into IS project management roles. To further validate the effectiveness of our pedagogy, we plan to conduct deeper analysis of the current data set and to expand the scope of our research to include feedback from project clients as well as the employers of our students. In addition, we plan to pursue a longitudinal case study to see if our students do indeed move into project management roles more readily. We invite faculty from other IS programs to utilize our pedagogical techniques for teaching IS project management and we welcome your feedback. We are pleased to provide you with more detail on course content, our teaching approach, and the methods/results of our study.

\section{REFERENCES}

1. Campbell, J. (2005). Management Career Watch, ComputerWorld, 41.

2. Davis, G., Gorgone, J., Valacich, J., Topi, H., Feinstein, D., \& Longenecker, H. (2002). IS 2002 Model Curriculum Guidelines for Undergraduate Degree Programs in IS. Association for Computing Machinery, Association for Information Systems, www.is2002.org.

3. Duncan, W. (1993). The Process of Project Management. Journal of Project Management, 24(3), 5-10.

4. Hingorani, K., Sankar, C. \& Kramer, S. (1998). Teaching Project Management Through An Information Technology-Based Method. Project Management Journal, 29(1).

5. Hoffman, T. (2003). IT Departments Face a Lack of Project Management Know-How, ComputerWorld, 16.

6. Klastorin, T. (2004). Project Management: tools and tradeoffs, Wiley.

7. Lee, D., Trauth, E., \& Farwell, D. (1995). Critical Skills and Knowledge Requirements of IS Professionals:A Joint Academic/Industry Investigation. MIS Quarterly, 19(3), 313-340.

8. Schwalbe, K. (2004). Information Technology Project Management, ( ${ }^{\text {rd }}$ ed). Thomson.

9. Smith, P. \& O'Neil, J. (2003). A review of action learning literature. Journal of Workplace Learning, 15(2), 63-69.

10. Ulema, M. (2004). A Comparative Analysis of Undergraduate Information Systems Curricula in Selected Business Schools. The Proceedings of ISECON 2004. Newport. 